\title{
Instrumentos internacionales de protección del derecho humano de asociación sindical *
}

\author{
International Instruments of Protection of the Human Right of Trade \\ Union Association
}

\begin{abstract}
Bertolt Delfín Rivera Colmenares
Abogado y Magíster en Derechos Humanos. Unidad Administrativa Especial, Dirección De Impuestos y Aduanas Nacionales - Colombia. bertoltrivera@gmail.com
\end{abstract}

Fecha de recepción: 4 de diciembre de 2016

Fecha de aprobación: 20 de mayo de 2017

Cómo citar este artículo/ to reference this article

Rivera Colmenares, B. (2017) https://revistas.uptc.edu.co/index.php/derecho_realidad/issue/view/549). Instrumentos internacionales de protección del derecho humano de asociación sindical. Derecho Y Realidad, 15(29): e8099.

Recuperado de https://revistas.uptc.edu.co/index.php/derecho_realidad/article/view/8099

Resumen: El presente trabajo es eminentemente jurídico-normativo y se desarrolla con una metodología documental, con la que se pretende construir una herramienta que permita una clara comprensión de los instrumentos internacionales aplicables en Colombia para garantizar el derecho humano de asociación sindical. En tal sentido, analiza las garantías del derecho humano de asociación sindical, consagradas en instrumentos internacionales, partiendo del estudio del sistema universal y americano, a fin de identificar las prerrogativas aplicables en el ordenamiento jurídico colombiano.

Palabras clave: derechos humanos, asociación sindical, libertad sindical, derecho constitucional.

Abstract: This work is eminently legal-normative and is developed with a documentary methodology, in which it is intended to build a tool that allows a clear understanding of the applicable international instruments in Colombia to guarantee the human right of trade union association. In this sense, it analyzes the guarantees of the human right of trade union association, enshrined in international instruments, based on the study of the universal and American system, in order to identify the applicable prerogatives in the Colombian legal system.

Keywords: human rights, trade union association, union freedom, Constitutional law.

\footnotetext{
* Artículo de investigación desarrollado dentro del programa de Maestría en Derechos Humanos de la UPTCTunja, el cual se encuentra inscrito en el campo jurídico-político y a la línea de investigación denominada "derechos humanos de víctimas", que aborda con perspectiva crítica de derechos humanos, relaciones normatividad-efectividad de derechos.
} 


\section{Introducción}

El Estado colombiano, regido por la Constitución de 1991, tiene dentro de sus fines esenciales garantizar la efectividad de los derechos consagrados en el texto constitucional. En el presente trabajo se encuentra especial interés respecto del derecho de asociación sindical consagrado en el artículo 39 de la Constitución Política, debido a que su ejercicio requiere de una específica protección, pues la experiencia ha demostrado que existen numerosas violaciones de derechos humanos a los trabajadores sindicalizados, a través de ataques sistemáticos que menoscaban el ejercicio sindical.

Estas violaciones han sido documentadas en importantes trabajos de investigación, dentro de los que se destacan el texto del Colectivo de Abogados José Alvear Restrepo (CAJAR) denominado Libertad sindical y derechos humanos en Colombia, el cual fue realizado para la Confederación General de Trabajadores Democráticos (CGTD) por Alirio Uribe Muñoz en el año 2000, y en el que se mencionan cifras y casos concretos de violaciones al derecho de asociación sindical, dentro de las que sobresale el asesinato en Colombia de 1336 sindicalistas en el periodo comprendido entre 1991 y 1999. También vale la pena citar la publicación Reconocer el pasado, construir el futuro, informe sobre la violencia contra sindicalistas y trabajadores sindicalizados 1984-2011, desarrollado por el Programa de las Naciones Unidas para el Desarrollo (PNUD), que permite dilucidar que la violencia contra quienes ejercen el derecho de asociación sindical ha sido una constante que no desaparece en la historia de Colombia; y en último término mencionamos la publicación de la Escuela Nacional Sindical Voces que no callan, informe sobre violaciones a los derechos humanos de los sindicalistas, y la situación de impunidad (2010-2015), elaborado por las investigadoras Sandra Milena Muños Cañas y Viviana Colorado López, en el que se señalan 192 violaciones a la vida, la libertad y la integridad contra sindicalistas, ocurridas tan solo en el año 2015.

En el ámbito internacional se observa que el índice global de la Confederación Sindical Internacional - CSI $^{I} 2016$, clasifica a Colombia dentro de los 10 peores países del mundo para los trabajadores, ubicándose al lado de países como Qatar, los Emiratos Árabes Unidos, Turquía, China, India, Camboya, Belarús, Irán y Guatemala, pues según el informe, en Colombia "los sindicalistas han venido siendo asesinados con total impunidad desde hace décadas", y a que "en 2015, se registraron 20 asesinatos de sindicalistas en Colombia -el mayor número que en ningún otro país" (Confederación Sindical Internacional [CSI], 2016, p. 24).

Esta problemática también ha sido reportada por los medios de comunicación, que constantemente se refieren a violaciones a derechos humanos de sindicalistas. Por ejemplo, el periódico El Espectador publica desde el 5 de junio de 2012 los siguientes titulares:

\footnotetext{
${ }^{1}$ La Confederación Sindical Internacional (CSI) es una central sindical, actualmente considerada la más grande del mundo, además cuenta con organizaciones regionales. Para nuestro caso opera la Organización Regional de las Américas (CSA).
} 
"Colombia, el país con más sindicalistas muertos en 2011", "Denuncian asesinato de 13 sindicalistas en Colombia este año" (17 de agosto del 2012) y "ONG denuncia en EE.UU. el asesinato de 105 sindicalistas en Colombia" (17 de abril del 2015); igualmente, el periódico El Tiempo, el 24 de junio y el 3 de julio de 2017, respectivamente, presenta las siguientes noticias: "Asesinato de líder sindical estaría relacionado con su actividad" y "Alerta por crímenes de sindicalistas en el suroccidente".

Aunado a lo anterior, se encuentra el reconocimiento tácito por parte del Estado colombiano de serias deficiencias en la protección de derechos humanos de los trabajadores sindicalizados $^{2}$, pues el 6 de abril del año 2011, en el marco de las negociaciones del Tratado de Libre Comercio con el Gobierno de Estados Unidos, suscribió un Plan de Acción Laboral en donde se comprometió (entre otras medidas) a: 1. La creación del Ministerio del Trabajo; 2. Reformar el Código Penal, para fortalecer la protección penal del derecho de asociación sindical; 3. Efectuar control a las cooperativas de trabajo asociado; 4. Control a las empresas de servicios temporales; 5. Castigar el uso ilegal de los pactos colectivos; 6. Delimitación de los servicios esenciales; 7. Cooperación, asesoramiento y asistencia técnica de la OIT; 8 . Cobertura del programa de protección para sindicalistas en riesgo; 9. Reformas a la justicia penal con miras a la implementación de medidas que contribuyan a la eliminación de la impunidad respecto de delitos cometidos contra sindicalistas (Ministerio del Trabajo, 2016).

En las siguientes líneas se hará una aproximación a los instrumentos internacionales de protección del derecho humano de asociación sindical, pues es imprescindible referirse al bien que es objeto de protección. Después se señalan los elementos que permiten articular normas internacionales con normas de derecho interno público en el Estado colombiano, para relacionarlos con los instrumentos internacionales, conformados tanto por las normas internacionales que pueden invocarse para la defensa del derecho humano de asociación sindical en Colombia, como por el sistema de la Organización de Naciones Unidas (ONU), también denominado "sistema universal" y por el sistema interamericano o regional. El panorama descrito permite concluir que es importante efectuar un estudio de los instrumentos internacionales, a fin de trazar rutas de defensa claras respecto a eventuales violaciones al derecho de asociación sindical. Al final se hace una recomendación.

\section{Instrumentos internacionales de protección del derecho humano de asociación sindical}

El derecho fundamental de asociación sindical ha sido reconocido internacionalmente como un derecho humano; sin embargo, históricamente se ha visto afectado por violaciones

\footnotetext{
${ }^{2}$ El Ministerio del Trabajo con ocasión de los primeros cinco años transcurridos desde la firma del Plan de Acción Laboral reconoce dentro de su informe que: "Uno de los aspectos más sensibles para la aprobación del TLC en el Congreso de Estados Unidos fueron las preocupaciones laborales en Colombia manifestadas constantemente por las organizaciones sindicales de ambos países. Por ello, el 6 de abril de 2011, Colombia y Estados Unidos acordaron el "Plan de acción relacionado con los derechos laborales" que allanó el camino para enviar el TLC Colombia-EE.UU. al Congreso de los Estados Unidos" (Ministerio del Trabajo, 2016, p. $3)$.
} 
constantes, las cuales se pueden categorizar así: 1) ataques directos graves, aquí podemos ubicar asesinatos de sindicalistas, masacres, desapariciones forzadas, desplazamiento forzado de trabajadores, amenazas a sindicalistas, secuestro de trabajadores y atentados contra sindicalistas; 2) medidas elusivas del derecho de asociación sindical, que consisten en acciones que aunque no prohíben el ejercicio sindical, menoscaban sus efectos; y por último, 3) medidas simbólicas, que se concretan en hechos que buscan desacreditar la idea del sindicato. Por eso es importante realizar un estudio sobre las garantías otorgadas mediante instrumentos internacionales respecto del derecho de asociación sindical, para convertirlos en los mecanismos idóneos para la protección de los trabajadores sindicalizados.

\section{Conceptualización de los derechos humanos e implementación de instrumentos internacionales}

El concepto de derechos humanos no responde a una sola definición, pues es plurivalente, de tal forma que para señalar su significado en algunas ocasiones se acude a fundamentos filosóficos (Beuchot, 2004), mientras que en otras se atiende a la finalidad ligándolo a valores supremos como el de la dignidad humana (Higuera, 2012). Sin embargo, estas no son las únicas posibilidades, pues como lo señala Pérez (1995), la noción de derechos humanos se torna imprecisa al ser usada con cargas argumentativas diferentes en ámbitos de carácter social, político y jurídico, haciéndose difícil determinar el alcance de la expresión. Esta situación ha sido abordada por autores como Norberto Bobbio, quien considera que en esta materia predomina la vaguedad conceptual, pues en la mayoría de los casos las nociones no se ocupan de definir realmente o lo hacen de forma poco satisfactoria (Bobbio, citado por Pérez, 1995).

En este sentido, aunque observamos las dificultades que impone abordar el concepto de derechos humanos, también podemos advertir que existen acciones que permiten disminuir la vaguedad en el uso de esta expresión, como lo es delimitar el concepto. Sobre este tema es ineludible hacer referencia al investigador Pérez (1995), quien desde un enfoque jurídico se propuso la tarea de delimitar el concepto de "derechos humanos", con la pretensión clara de aproximarse a una ciencia de los derechos humanos, sentando bases importantes para que el concepto no caiga en el dogmatismo. Por lo tanto, su importante esfuerzo argumentativo partió del análisis lingüístico y estructural de los derechos humanos, para lograr una sólida deliberación racional y, finalmente, proponer el siguiente concepto de derechos humanos: "conjunto de facultades e instituciones que, en cada momento histórico concretan las exigencias de la dignidad, la libertad y la igualdad humanas, las cuales deben ser reconocidas positivamente por los ordenamientos jurídicos nacionales e internacionales" (Pérez, 1995, p. 48).

También es relevante el referente conceptual de derechos humanos que Barbero (2014) utiliza en sus estudios sobre protección internacional de los derechos humanos, pues citando a Nowak (2009), los define como "la suma de los derechos civiles, políticos, económicos, sociales, culturales y colectivos establecidos en instrumentos internacionales de derechos humanos" (Barbero, 2014, p. 19), y, a su vez, citando a Ventura (2007), los señala como "aquellos derechos fundamentales que empoderan a los seres humanos para 
modelar sus vidas de acuerdo con la libertad, la igualdad y el respeto por la dignidad humana" (Barbero, 2014, p. 19).

De lo expuesto, se evidencia la importancia de dos elementos, el primero es el de la fundamentación de los derechos humanos, y el segundo, el de su reconocimiento positivo ${ }^{3}$; es decir, a través de normas jurídicas, a efectos de lograr la materialización, lo que refleja la búsqueda constante del modo más seguro de darles efectividad y vigencia.

Sin embargo, existen posturas diversas sobre la forma en que deben orientarse los esfuerzos que propenden la materialización de los derechos humanos. Así, Bobbio (1991) expresa:

El problema que se nos presenta en efecto no es filosófico, sino jurídico y, en sentido más amplio, político. No se trata tanto de saber cuáles son y cuántos son estos derechos, cuál es su naturaleza y fundamento, si son derechos naturales o históricos, absolutos o relativos, sino cuál es el modo más seguro de garantizarlos, para impedir que, a pesar de las declaraciones solemnes, sean continuamente violados. (1991, p.64)

En este orden de ideas, consideramos que el ejercicio que debe desarrollarse alrededor de los derechos humanos es interdisciplinar, para fortalecerlos desde todos los frentes posibles, pues advertimos la importancia tanto de la fundamentación filosófica, como del reconocimiento jurídico y político.

En la presente investigación se entienden los derechos humanos como el conjunto de derechos establecidos en instrumentos nacionales e internacionales, los cuales son necesarios para dar desarrollo a la dignidad humana ${ }^{4}$, entendida esta, en primera instancia, como un derecho, lo que permite hacerla exigible; y en segunda instancia, como un valor, por el cual existen prerrogativas especiales que son inherentes al ser humano, y en tal sentido, se convierte en la base de toda la gama de derechos posibles ${ }^{5}$.

Realizada la aproximación al concepto de los derechos humanos, debe indicarse que estos poseen unas características que los identifican, las cuales, de acuerdo con el investigador Carpizo (2011), son: universalidad, historicidad, progresividad, aspecto protector, indivisibilidad y eficacia directa. Enseguida nos referiremos brevemente a cada una de ellas:

\footnotetext{
3 Al respecto, Alexy (1995) menciona: "Los derechos humanos sólo pueden desenvolver su pleno vigor cuando se les garantiza a través de normas de derecho positivo, esto es, transformados en derecho positivo. Este es el caso, por ejemplo, de su incorporación como derecho obligatorio en el catálogo de derechos fundamentales de una constitución" (p.93).

${ }^{4}$ Sobre la noción de dignidad humana, Santo Tomás de Aquino considera que "está vinculada a la visión misma de persona. La noción de persona implica de suyo una gran dignidad, inviolable e inalienable" (Beuchot, 2004, p.50).

${ }^{5}$ Es importante mencionar que a lo largo de la historia de los orígenes de los derechos humanos se encuentran desarrollos en los que se indican que los hombres tiene ciertos derechos innatos, esto es, por su condición de hombres; por ejemplo, en el primer artículo de la Declaración de Derechos del Pueblo de Virginia de 1776 se expresa que los hombres tienen ciertos derechos inherentes; de igual manera, el artículo 2 de la Declaración de Derechos del Hombre y del Ciudadano de 1789 señala que la finalidad esencial del Estado es la conservación de los derechos naturales e imprescriptibles del hombre (Barbero, 2014).
} 
Universalidad: hace referencia a que todos los seres humanos tienen derechos con independencia del lugar físico en que se encuentren, es una característica ligada a la posibilidad de hacerlos exigibles en cualquier tiempo y lugar.

Historicidad: contempla que el reconocimiento de los derechos humanos y su contenido es el resultado de la historia, en consecuencia, estos atienden las necesidades y problemáticas gestadas en diferentes contextos sociales y culturales.

Progresividad: implica que cada vez se aspira a un mayor nivel de derechos; por lo tanto, esta característica conlleva la irreversibilidad de los derechos.

Aspecto protector: admite que se ampara a toda persona humana, es decir, que el contenido de los derechos o las prerrogativas especiales que se garantizan son inherentes al ser humano.

Indivisibilidad: indica que todos los derechos forman una unidad, de tal forma que son interdependientes entre sí, apoyándose mutuamente.

Eficacia directa: significa que los derechos humanos reconocidos en la Constitución y en los instrumentos internacionales ratificados por un país vinculan obligatoriamente a todos los poderes públicos, así como a autoridades, grupos y personas, y para ello no es necesario que una ley desarrolle los alcances de ese derecho humano (Carpizo, 2011, pp. 23-24).

No obstante, debe advertirse que estas características pueden encontrar variaciones entre los diferentes doctrinantes, por ejemplo Cassese (1991) refiere la existencia de tendencias teóricas que se cuestionan sobre si los derechos humanos son realmente universales o no. Situación de la que no nos ocuparemos, por cuanto no es el objeto del presente trabajo. Sin embargo, vale la pena señalar que en el ámbito de los derechos humanos existe una constante búsqueda por "obtener un mínimo de preceptos comunes en virtud de los cuales pueda asegurarse por lo menos el respeto a los fundamentos esenciales de la dignidad humana, en cualquier lugar del mundo" (Cassese, 1991, p.80).

Por su parte, la Conferencia Mundial de Derechos Humanos realizada en Viena en 1993, dentro de su Declaración y Programa de Acción ${ }^{6}$ señaló: "Todos los derechos humanos son universales, indivisibles e interdependientes y están relacionados entre sí”. Así las cosas, se observa un consenso en el escenario internacional respecto de las características que contienen los derechos humanos, situación que favorece la protección, la promoción y la prevención en materia de derechos humanos.

\footnotetext{
6 La Declaración y Programa de Acción de Viena de 1993, puede ser consultada en: http://www.ohchr.org/Documents/Events/OHCHR20/VDPA_booklet_Spanish.pdf
} 
Para concluir, por el momento nos basta con decir que estos son algunos derechos humanos reconocidos internacionalmente ${ }^{7}$ :

Derecho a la vida.

Derecho a la integridad personal.

Derecho a la libertad.

Derecho a la libertad de opinión y expresión.

Derecho a la libertad de reunión y asociación.

Derecho al trabajo.

Derecho a fundar sindicatos y a sindicalizarse para la defensa de sus intereses.

Derecho a la presunción de inocencia.

Derecho a la educación.

Derecho a la intimidad.

En este punto nos ocuparemos de los elementos que permiten aplicar instrumentos internacionales de protección de derechos humanos dentro del ordenamiento jurídico colombiano. Por lo tanto, comenzaremos por indicar que de conformidad con lo consignado en el artículo 1 de la Constitución de 1991, Colombia es un Estado social de derecho, lo que implica un elevado respeto por los derechos consagrados en el texto constitucional y, a su vez, por los contenidos en tratados internacionales de derechos humanos, pues el constituyente de 1991 plasmó en la Constitución normas sobre convenios internacionales que hacen parte de la legislación interna (art. 53 C.N.) ${ }^{8}$, la prevalencia en el orden interno de tratados y convenios ratificados sobre derechos humanos (art. 93 C.N.), derechos y garantías inherentes a la persona humana que no figuran expresamente ni en la Constitución ni en los convenios internacionales (art. 94 C.N.), los límites que imponen los tratados internacionales ratificados por Colombia (art. 101 C.N.) y la imposibilidad de suspender los derechos humanos y las libertades fundamentales en los estados de excepción (art. 214 C.N.). Se vislumbra así un nuevo escenario en donde se les otorga fuerza jurídica de rango constitucional a normas internacionales, lo que se ha denominado bloque de constitucionalidad $^{9}$, pues mediante los postulados constitucionales referidos se logra articular normas supranacionales con normas de derecho interno público, permitiendo que la protección de derechos tenga alcances más allá del simple texto formal constitucional.

Al respecto, se precisa que la Corte Constitucional colombiana utilizó por primera vez el concepto de "bloque de constitucionalidad" mediante sentencia C-225 de 1995 (Uprimny, 2005), siendo magistrado ponente Alejando Martínez Caballero, allí expresó:

\footnotetext{
${ }^{7}$ Estos derecho se encuentran consignados en instrumentos internacionales, dentro de ellos en la Declaración Universal de Derechos Humanos de 1948, así como en las distintas disposiciones que ha producido tanto la Organización de Naciones Unidas (ONU), como los sistemas regionales de derechos humanos.

${ }^{8}$ El artículo 53 de la Constitución Política de Colombia es la fuente de los principios del derecho del trabajo (Jaramillo, 2015).

${ }^{9}$ Refiriéndose al bloque de constitucionalidad, Uprimny (2005) señala: "En efecto, esta noción amplía los términos del debate constitucional, tanto en los procesos de control abstracto como en las acciones de tutela y amparo, pues implica que las normas a tener en cuenta para resolver una controversia judicial no son exclusivamente los artículos de la constitución, ya que otras disposiciones y principios pueden tener también relevancia para decidir esos asuntos" (pp.3-4).
} 
El bloque de constitucionalidad está compuesto por aquellas normas y principios que, sin aparecer formalmente en el articulado del texto constitucional, son utilizados como parámetros del control de constitucionalidad de las leyes, por cuanto han sido normativamente integrados a la Constitución, por diversas vías y por mandato de la propia Constitución. Son pues verdaderos principios y reglas de valor constitucional, esto es, son normas situadas en el nivel constitucional, a pesar de que puedan a veces contener mecanismos de reforma diversos al de las normas del articulado constitucional stricto sensu. (Sentencia C-225, 1995, citada por Uprimny, 2005, p. 17)

Sobre el mismo tema, la Corte Constitucional colombiana en sentencia C-582 de 1999, magistrado ponente Alejandro Martínez Caballero, indicó cuáles son los tratados y convenios que hacen parte del bloque de constitucionalidad, en los siguientes términos:

No todos los tratados y convenios internacionales hacen parte del bloque de constitucionalidad, pues tal y como la jurisprudencia de esta Corporación lo ha señalado en varias oportunidades, "los tratados internacionales, por el sólo hecho de serlo, no forman parte del bloque de constitucionalidad y, por tanto, no ostentan una jerarquía normativa superior a la de las leyes ordinarias". En efecto, la Corte ha señalado que, salvo remisión expresa de normas superiores, sólo constituyen parámetros de control constitucional aquellos tratados y convenios internacionales que reconocen derechos humanos (i) y, que prohíben su limitación en estados de excepción (ii). Es por ello, que integran el bloque de constitucionalidad, entre otros, los tratados del derecho internacional humanitario, tales como los Convenios de Ginebra, los Protocolos I y II y ciertas normas del Pacto de San José de Costa Rica. (Sentencia C-582, 1999)

De igual forma, es relevante hacer referencia al pronunciamiento de la Corte Constitucional en la sentencia C-067 de 2003 (magistrado ponente Marco Gerardo Monroy Cabra), pues allí se reconoce como criterio interpretativo la doctrina de las jurisdicciones internacionales, es decir, que dichos pronunciamientos al igual que los convenios no ratificados por Colombia se convierten en herramientas interpretativas de relevancia constitucional.

Hasta este punto se hizo una conceptualización de los derechos humanos, lo que permitió aproximarnos a dos elementos: el primero es el de las diferentes formas de fundamentación, y el segundo el del reconocimiento positivo. Acto seguido, nos referirnos a las características de los derechos humanos, para posteriormente establecer la forma en que se entenderán los derechos humanos dentro de la presente investigación; una vez culminada esa fase se señalan los mecanismos establecidos en el ordenamiento jurídico colombiano para la articulación de normas supranacionales y nacionales. A continuación nos referiremos a los instrumentos internacionales, los cuales están conformados tanto por las normas internacionales que pueden invocarse para la defensa del derecho humano de asociación sindical en Colombia, como por el sistema de la Organización de Naciones Unidas (ONU), también denominado "Sistema Universal" y por el Sistema Interamericano o regional. 


\section{Elementos que permiten articular normas internacionales con normas de derecho interno público en el Estado colombiano}

Es de gran interés abordar el estudio del sistema universal de la ONU, así como el del Sistema Interamericano de Derechos Humanos, por cuanto los tratados y convenios internacionales son importantes en la medida en que exista una interacción entre el orden interno y el internacional, que permita el cumplimiento de los derechos establecidos en instrumentos convencionales (Brotóns, 2007). Por eso es relevante examinar de dónde surgen los principios y normas internacionales y, a su vez, cómo se han venido adoptando en el Estado colombiano.

\subsection{Sistema Universal}

El Sistema Universal nace como respuesta a los graves sucesos ocurridos en la Segunda Guerra Mundial (Higuera, 2012), la cual se desarrolló entre los años 1939 a 1945 , confrontación que estuvo marcada por crímenes contra la humanidad. Esta situación dio origen a una visión universalista de los derechos humanos (Botero \& Guzmán, s.f.), pues busca que su protección se de a escala mundial; para tal fin, se producen dos instrumentos: la Carta de las Naciones Unidas, firmada el 26 de junio de 1945 en San Francisco, Estados Unidos, y la Declaración Universal de Derechos Humanos de 1948 (Brotóns, 2007). Es de anotar que posteriormente, en el año de 1966 y dentro del marco de la ONU ${ }^{10}$, se suscriben el Pacto Internacional de Derechos Civiles y Políticos y el Pacto Internacional de Derechos Económicos, Sociales y Culturales, perfilándose así una verdadera estructura de protección internacional de los derechos humanos (Barbero, 2014).

Actualmente, su estructura está conformada por dos clases de órganos, principales y convencionales; dentro de los primeros están la Asamblea General, el Consejo de seguridad, el Consejo Económico y Social y la Corte Internacional de Justicia; y dentro de los segundos se hallan: el Comité de Derechos Humanos, el Comité de Derechos Económicos, Sociales y Culturales, el Comité contra la Tortura, el Comité de los Derechos del Niño, el Comité para la Eliminación de la Discriminación Racial, el Comité para la Eliminación de la Discriminación contra la Mujer y el Comité de Derechos de los Trabajadores Migrantes, todos ellos orientados a proteger los derechos y las libertades individuales en el ámbito internacional.

Respecto a la labor de la ONU, se evidencia que trabaja en materializar los derechos que han sido reconocidos y, así mismo, en el establecimiento de nuevos derechos, desde una concepción universalista, atendiendo a las necesidades históricas, de tal forma que se ha consolidado como el principal productor de documentos en materia de derechos humanos (Barbero, 2014). Es importante señalar que en el Sistema Universal se ha reconocido el derecho de asociación sindical como un derecho humano, por lo tanto es necesario identificar puntualmente los instrumentos en los que se ha consignado el derecho en mención, para luego rastrear la forma en que se ha ejecutado o garantizado en el marco del Sistema Universal. En tal sentido, a continuación se hace un esfuerzo por identificar las

${ }^{10}$ La ONU es una organización intergubernamental, formada por Estados (Cassese, 1991). 
disposiciones supranacionales que contienen: 1) los principios rectores del Sistema Universal y 2) el derecho humano de asociación sindical.

Tabla 1. Instrumentos que contienen los principios rectores del Sistema Universal en Colombia

\begin{tabular}{|c|c|c|}
\hline INSTRUMENTO & $\begin{array}{c}\text { FECHA DE } \\
\text { INCORPORACIÓN }\end{array}$ & $\begin{array}{l}\text { LEY NACIONAL DE } \\
\text { INCORPORACIÓN } \\
\text { (COLOMBIA) }\end{array}$ \\
\hline Carta de las Naciones Unidas & 26 de junio de 1945 & $\begin{array}{l}\text { No requiere. Hace parte del } \\
\text { ius cogens }{ }^{I I} \text {. }\end{array}$ \\
\hline $\begin{array}{l}\text { Declaración Universal de Derechos } \\
\text { Humanos }\end{array}$ & 10 de diciembre de 1948 & $\begin{array}{l}\text { No requiere. Aplica } \\
\text { principio general del } \\
\text { derecho de remisión } \\
\text { normativa. }\end{array}$ \\
\hline $\begin{array}{l}\text { Pacto Internacional de } \\
\text { Civiles y Políticos }\end{array}$ & 16 de diciembre de 1966 & Ley 74 de 1968 \\
\hline $\begin{array}{l}\text { Pacto Internacional de Derechos } \\
\text { Económicos, Sociales y Culturales }\end{array}$ & 16 de diciembre de 1966 & Ley 74 de 1968 \\
\hline
\end{tabular}

Como se observa en la Tabla 1, la Carta de las Naciones Unidas hace parte del ius $\operatorname{cogens}^{12}$, en consecuencia, no requiere ley de incorporación nacional (Brotóns, 2007). En su artículo 2 se contempla que los principios allí contenidos deben ser respetados por los Estados miembros y, a su vez, por los que no lo suscribieron; sin embargo, aun cuando no requiera ley de incorporación, debe mencionarse que el Estado colombiano a través de sus representantes suscribió la Carta de las Naciones Unidas en el año 1945 (Tirado, s.f.).

La Declaración Universal de Derechos Humanos fue proclamada por la Asamblea General de las Naciones Unidas en 1948, y es reconocida en el Pacto Internacional de Derechos Civiles y Políticos, así como en el Pacto Internacional de Derechos Económicos, Sociales y Culturales. En tal sentido, no requiere ley de incorporación en Colombia, pues aplica el principio general del derecho de remisión, que implica que si una norma remite a otra, la remitida tiene el mismo valor, de tal forma que basta con que hayan sido aprobados los pactos antes mencionados para que la Declaración Universal tenga vigencia y sea aplicable en nuestro ordenamiento jurídico. Por otra parte, este instrumento se considera relevante en la historia de los derechos humanos, pues consagra los derechos humanos fundamentales que deben protegerse en todo el mundo.

El Pacto Internacional de Derechos Civiles y Políticos de 1966 hace parte del bloque de constitucionalidad colombiano y dentro su contenido está incluido el derecho humano de asociación sindical, específicamente en el numeral 1 del artículo 22, en los siguientes términos: "Toda persona tiene derecho a asociarse libremente con otras, incluso el derecho

\footnotetext{
${ }^{11}$ Tratándose de derechos humanos, el ius cogens implica que en ausencia de ratificación de un tratado, pacto o convenio que positivice el derecho imperativo, esto no excusa al Estado de garantizarlo y protegerlo, ni al juez de aplicarlo y protegerlo (Gómez, 2006).

${ }^{12}$ El artículo 53 común de las Convenciones de Viena, contiene la obligación de carácter general que tienen los Estados de respeto y garantía del ius cogens.
} 
a fundar sindicatos y afiliarse a ellos para la protección de sus intereses”. Cabe señalar que con anterioridad a la Constitución colombiana de 1991 existían normas orientadas a la protección del derecho humano de asociación sindical, aun cuando no tuvieran rango constitucional, como en el caso de la Ley 74 de 1968, que en la actualidad tiene rango constitucional.

En cuanto al Pacto Internacional de Derechos Económicos Sociales y Culturales de 1966, debe mencionarse que nace con plena observancia de los principios consagrados en la Carta de la ONU y que contiene derechos que se derivan de la dignidad inherente a la persona humana. Dentro de ellos se reconoció el derecho a fundar sindicatos y a afiliarse en ellos; es así como, el artículo 8 numeral 1 literal a señala:

Artículo 8.

1. Los Estados Partes en el presente Pacto se comprometen a garantizar:

a) El derecho de toda persona a fundar sindicatos y a afiliarse al de su elección, con sujeción únicamente a los estatutos de la organización correspondiente, para promover y proteger sus intereses económicos y sociales. No podrán imponerse otras restricciones al ejercicio de este derecho que las que prescriba la ley y que sean necesarias en una sociedad democrática en interés de la seguridad nacional o del orden público, o para la protección de los derechos y libertades ajenos.

Este es un importante avance para la "autonomía sindical", por cuanto es el primer paso para impedir intervenciones directas del Estado, sin que ello quiera decir que no exista regulación, pues la misma norma contempla límites establecidos en la ley.

\subsection{Organización Internacional del Trabajo (OIT)}

Continuando con la identificación de las disposiciones supranacionales que buscan garantizar el derecho humano de asociación sindical, es necesario referirnos a la normativa de la OIT (Organización Internacional del Trabajo), puesto que Colombia es miembro de esta organización desde $1919 \mathrm{y}$, a su vez, porque producto de la 27 ${ }^{\mathrm{a}}$ Reunión de la Conferencia Internacional del Trabajo, llevada a cabo en 1946, la OIT se convirtió en la primera agencia especializada de las Naciones Unidas (Montt, 1998). Así las cosas, es necesario mencionar que la OIT produce dos tipos de regulaciones: convenios y recomendaciones $^{13}$; los primeros son acuerdos con vocación normativa, por cuanto deben ser ratificados por los Estados miembros para que puedan convertirse en derecho interno, mientras que los segundos contienen directrices orientadoras y propuestas para que sean tenidas en cuenta por los Estados miembros (Borrajo, 2014).

\footnotetext{
${ }^{13}$ En sentencia T-568 de 1999, la Corte Constitucional concluyó: "Las recomendaciones de los órganos de control y vigilancia de la OIT, no pueden ser ignoradas: cuando resultan de actuaciones del Estado contrarias a los tratados internacionales aludidos en el artículo 93 Superior, aunque no sean vinculantes directamente, generan una triple obligación en cabeza de los Estados: deben 1) ser acogidas y aplicadas por las autoridades administrativas; 2) servir de base para la presentación de proyectos legislativos; y 3) orientar el sentido y alcance de las órdenes que el juez de tutela debe impartir para restablecer los derechos violados o amenazados en ése y los casos que sean similares".
} 
En este sentido, es necesario examinar los convenios de la OIT que han sido ratificados por Colombia, a efectos de establecer con claridad cuáles son aplicables en el ordenamiento jurídico colombiano respecto del derecho humano de asociación sindical, pues ya se han ratificado 61 convenios sobre diferentes temas relacionados con el derecho al trabajo ${ }^{14}$.

En cuanto a los derechos humanos de asociación sindical, libertad sindical y negociación colectiva, se encuentran ratificados por Colombia los siguientes convenios:

Tabla 2. Convenios ratificados por Colombia sobre asociación sindical, libertad sindical y negociación colectiva

\begin{tabular}{|c|c|c|c|}
\hline INSTRUMENTO & TEMA QUE REGULA & AÑO DE CREACIÓN & $\begin{array}{l}\text { LEY DE } \\
\text { INCORPORACIÓN }\end{array}$ \\
\hline Convenio 87 de la OIT & $\begin{array}{l}\text { Sobre libertad sindical y } \\
\text { la protección del derecho } \\
\text { de sindicación. }\end{array}$ & 1948 & Ley 26 de 1976 \\
\hline Convenio 98 de la OIT & $\begin{array}{lll}\text { Sobre el derecho } & \text { de } \\
\text { sindicación y } & \text { de } \\
\text { negociación colectiva. }\end{array}$ & 1949 & Ley 27 de 1976 \\
\hline Convenio 151 de la OIT & $\begin{array}{l}\text { Sobre la protección del } \\
\text { derecho de sindicación y } \\
\text { los procedimientos para } \\
\text { determinar las } \\
\text { condiciones de empleo } \\
\text { en la administración } \\
\text { pública. }\end{array}$ & 1978 & Ley 411 de 1997 \\
\hline Convenio 154 de la OIT & $\begin{array}{l}\text { Sobre la negociación } \\
\text { colectiva. }\end{array}$ & 1981 & Ley 524 de 1999 \\
\hline
\end{tabular}

Es de anotar que los convenios relacionados fueron incorporados a la legislación interna ${ }^{15}$, sin embargo, solo hacen parte del bloque de constitucionalidad ${ }^{16}$ los convenios 87,98 y 154, en cuanto se refieren a derechos humanos fundamentales en el trabajo. Situación que los convierte en referentes necesarios para la interpretación de los derechos de los trabajadores (Corte Constitucional, sentencia C-349 de 2009).

Sobre este tema, la Corte Constitucional ha sido clara al indicar que aunque todos los convenios de la OIT que han sido debidamente ratificados por Colombia hacen parte de la legislación interna, no todos forman parte del bloque de constitucionalidad ${ }^{17}$, puesto que

\footnotetext{
14 Sobre los convenios de la Organización Internacional del Trabajo (OIT) ratificados por Colombia puede consultarse el registro disponible http://www.ilo.org/dyn/normlex/es/f?p=1000:11200:0::NO:11200:P11200_COUNTRY_ID:102595

${ }^{15}$ Los convenios de la OIT debidamente ratificados por Colombia son fuente principal y se pueden aplicar directamente para resolver controversias en el ámbito laboral.

${ }^{16} \mathrm{Al}$ respecto pueden consultarse las sentencias C-466/08 y C-349/09 proferidas por la Corte Constitucional colombiana.

${ }^{17}$ La Corte Constitucional colombiana, mediante sentencia C-280 de 2007, indica que "algunos" convenios de la OIT pertenecen al bloque de constitucionalidad en sentido estricto, puesto que no todos los convenios hacen parte de ese bloque.
} 
algunos no reconocen ni regulan derechos humanos, sino que se ocupan de aspectos administrativos, estadísticos o de otra índole no constitucional; en tal sentido, le corresponde a la Corte Constitucional señalar qué convenios hacen parte del bloque de constitucionalidad en sentido estricto y cuáles en sentido lato ${ }^{18}$.

En este orden de ideas, es oportuno indicar que la Corte Constitucional refiriéndose al bloque de constitucionalidad y a los convenios de la OIT, mediante sentencia C-018 de 2015, proferida dentro del expediente D-10.309, siendo magistrado ponente Gabriel Eduardo Mendoza Martelo, expresó:

En reiterada jurisprudencia, a este bloque se han adscrito algunos Convenios de la Organización Internacional del Trabajo y, en particular, los identificados con los números 87 y 98. En efecto, mediante las Leyes 26 y 27 de 1976 el Estado colombiano ratificó los Convenios 87 y 98 de la OIT que, respectivamente, se refieren a la libertad sindical y al derecho de negociación colectiva, lo cual le ha permitido a la Corporación sostener que estos Convenios integran la legislación interna, así como del bloque de constitucionalidad, entendido en su sentido estricto, lo que significa que "hacen parte del parámetro de control constitucional de las normas legales que regulan la materia". Este reconocimiento de los Convenios 87 y 98 de la Organización Internacional del Trabajo como integrantes del bloque de constitucionalidad en sentido estricto lo ha hecho la Corte de manera expresa. (Sentencia C-018 de 2015)

Del pronunciamiento reseñado se concluye que efectivamente los convenios 87 y 98 hacen parte del bloque de constitucionalidad en sentido estricto; no obstante, consideramos que la Corte Constitucional efectúa divisiones injustificadas al referirse al bloque de constitucionalidad en sentido lato y estricto, pues las normas que lo conforman deben tener la misma fuerza o valor al ser usadas como parámetro de control de constitucionalidad y como referente obligatorio en materia de interpretación, y no deben crearse categorías que no contempla la Constitución, pues ellas resultan irrelevantes y no aportan a la resolución de casos. En el mismo sentido, se evidencia que el uso inapropiado de esas categorías conlleva el desconocimiento del principio general de derecho de remisión ${ }^{19}$, que implica que si una norma remite a otra, la remitida tiene el mismo valor, tanto así que la Constitución en su artículo 93 contiene de forma implícita el principio de remisión en materia de derechos humanos.

De lo expuesto se concluye que los convenios referidos no son parámetros supletorios, sino que contienen carácter normativo obligatorio, pues se encuentran al mismo nivel de la

\footnotetext{
${ }^{18}$ Sobre este tema puede consultarse la sentencia C-401/05 proferida por la Corte Constitucional colombiana, magistrado ponente Manuel José Cepeda Espinosa.

${ }^{19}$ En cuanto a la remisión, Uprimny (2005) manifiesta: "Es necesario tener en cuenta que las constituciones no son códigos totalmente cerrados, ya que los textos constitucionales pueden hacer remisiones, expresas o tácitas, a otras reglas y principios, que sin estar en la constitución, tienen relevancia en la práctica constitucional en la medida en que la propia constitución establece que esas otras normas tienen una suerte de valor constitucional. Así, los casos más evidentes son aquellos en donde una constitución expresamente señala que, por ejemplo, ciertos tratados de derechos humanos tienen rango constitucional, tal y como lo hacen varias constituciones latinoamericanas". (p. 3), (negrilla fuera del texto).
} 
Constitución, por lo que deben ser aplicados tanto por los particulares como por las autoridades públicas, para dar efectividad a los derechos humanos allí contemplados.

\subsection{Sistemas regionales}

En el ámbito regional también se han configurado organizaciones para proteger los derechos humanos. En la actualidad existen tres sistemas regionales, a saber: europeo, africano y americano. A continuación nos ocuparemos del Sistema Americano, que también es conocido como Sistema Interamericano, pues este es el que se aplica a Colombia.

Iniciaremos por recordar que la Organización de Estados Americanos (OEA) es la encargada de la defensa de derechos humanos en el continente americano y que en consecuencia tiene normativa específica, órganos propios y mecanismos de control. Su trabajo está orientado inicialmente por la Declaración Americana de los Derechos y Deberes del Hombre, y por la Carta de la OEA, documentos suscritos en la ciudad de Bogotá en 1948. Este último instrumento ha sido objeto de varias enmiendas, dentro de las que se encuentran los protocolos de Buenos Aires de 1967, de Cartagena de indias de 1985, de Managua de 1993 y el de Washington de 1992.

Así mismo, cabe mencionar que dentro del Sistema Americano se aplica la Convención Americana sobre Derechos Humanos de 1969, conocida como Pacto de San José, la cual dentro de su preámbulo señala que tiene observancia de los principios contenidos en la Declaración Universal de los Derechos Humanos de 1948 y en la Declaración Americana de los Derechos y Deberes del Hombre de1948.

Al respecto resulta pertinente señalar mediante qué leyes fueron aprobados estos instrumentos dentro del ordenamiento jurídico colombiano.

Tabla 3. Instrumentos del Sistema Americano y aplicación en Colombia

\begin{tabular}{|c|c|c|c|}
\hline INSTRUMENTO & OBSERVACIONES & AÑO DE CREACIÓN & $\begin{array}{c}\text { LEY DE } \\
\text { INCORPORACIÓN }\end{array}$ \\
\hline $\begin{array}{l}\text { Convención Americana } \\
\text { sobre Derechos Humanos } \\
\text { (Pacto de San José) }\end{array}$ & $\begin{array}{l}\text { Señala deberes de los } \\
\text { Estados y derechos } \\
\text { protegidos, así mismo, } \\
\text { establece la estructura, la } \\
\text { competencia y los } \\
\text { procedimientos de los } \\
\text { órganos de la Organización } \\
\text { de Estados Americanos. }\end{array}$ & 1969 & Ley 16 de 1972 \\
\hline $\begin{array}{l}\text { Declaración Americana de } \\
\text { los Derechos y Deberes del } \\
\text { Hombre }\end{array}$ & $\begin{array}{l}\text { Es reconocida en el } \\
\text { preámbulo de la } \\
\text { Convención Americana } \\
\text { sobre Derechos Humanos } \\
\text { de } 1969 \text { y tiene valor como } \\
\text { norma de remisión. }\end{array}$ & 1948 & No requiere \\
\hline $\begin{array}{l}\text { Declaración Universal de } \\
\text { Derechos Humanos }\end{array}$ & $\begin{array}{l}\text { Es reconocida en el } \\
\text { preámbulo de la } \\
\text { Convención Americana } \\
\text { sobre Derechos Humanos } \\
\text { de } 1969 \text { y tiene valor como } \\
\text { norma de remisión. }\end{array}$ & 1948 & No requiere \\
\hline
\end{tabular}


En cuanto al derecho humano de asociación sindical, debe mencionarse que se encuentra contenido en los instrumentos aplicables en el Sistema Interamericano. Así, por ejemplo, en la Declaración Universal de los Derechos Humanos de 1948, específicamente en los artículos 20.1 y 23.4, se proclama el derecho de toda persona a reunirse libremente y a asociarse pacíficamente, a su vez, a fundar sindicatos y a sindicarse para la defensa de sus intereses. En el mismo sentido, la Convención Americana sobre Derechos Humanos de 1969 (Pacto de San José) en su artículo 16 consagra y desarrolla el derecho de libertad de asociación, teniendo como presupuestos tres elementos: el primero implica que toda persona tiene derecho a asociarse libremente con fines de cualquier índole (ideológicos, políticos, laborales, económicos, etc.), el segundo tiene que ver con que el ejercicio de asociación solo puede estar sujeto a las restricciones previstas por la ley, que sean necesarias en una sociedad democrática, y el tercero es relativo a la posibilidad de imponer restricciones al ejercicio de asociación de los miembros de fuerzas armadas y de policía.

Por lo tanto, se encuentran bases sólidas para la protección, la promoción y la prevención del derecho humano de asociación sindical dentro del Sistema Americano. Bajo estos presupuestos es pertinente mencionar que para atender las violaciones de derechos humanos en la región se crearon dos entidades, la Comisión Interamericana de Derechos Humanos y la Corte Interamericana de Derechos Humanos.

La Comisión Interamericana de Derechos Humanos tiene un papel importante en materia de protección y promoción de los derechos humanos y es competente para atender asuntos de los Estados parte de la Convención Americana sobre Derechos Humanos y de los miembros de la OEA; sus funciones ${ }^{20}$ son las de estimular la conciencia de los derechos humanos en América, formular recomendaciones a los Estados miembros a fin de que adopten medidas a favor de los derechos humanos, preparar estudios e informes de acuerdo con sus responsabilidades, atender consultas que formulen los Estados miembros en relación con derechos humanos, actuar frente a peticiones no gubernamentales que contengan denuncias o quejas de violación de la Convención Americana por un Estado miembro del mismo instrumento $^{21}$, entre otras.

Por otra parte, la Corte Interamericana de Derechos Humanos funge como instancia contenciosa y tiene competencia sobre los Estados parte de la Convención Americana sobre Derechos Humanos que de forma expresa hayan manifestado someterse a su jurisdicción. Esta instancia está facultada para interpretar y aplicar las normas interamericanas de derechos humanos, sus decisiones están orientadas a proteger el derecho demandado u ordenar una indemnización a la víctima por una violación irreparable.

\footnotetext{
${ }^{20}$ Las funciones de la Comisión se encuentran detalladas en el artículo 44 de la Convención Americana sobre Derechos Humanos de 1969, disponible en: http://www.hchr.org.co/documentoseinformes/documentos/html/pactos/conv_americana_derechos_humanos. $\underline{\mathrm{html}}$

${ }^{21}$ De conformidad con el artículo 46 de la Convención Americana sobre Derechos Humanos de 1969, es necesario interponer o agotar los recursos de la jurisdicción interna; sin embargo, esta condición admite excepciones, la cuales están contempladas en el numeral 2 de la misma norma.
} 
Sin embargo, los casos de los que conoce la Corte Interamericana de Derechos Humanos son tratados con antelación por la Comisión, que investiga las presuntas violaciones y de haber mérito los remite a la Corte para que decida sobre la existencia o no de una vulneración a los derechos contemplados en la Convención Americana sobre Derechos Humanos; su trabajo finaliza con un fallo sobre el que no procede recurso de apelación. Es de anotar que esta instancia examina únicamente la responsabilidad de los Estados parte sobre graves violaciones de derechos humanos.

Otra competencia de la Corte Interamericana de Derechos Humanos es la consultiva, la cual está contemplada en el artículo 64 de la Convención Americana, y en virtud de ella está facultada para pronunciarse sobre consultas elevadas por los Estados miembros acerca de la interpretación de la convención o de otros tratados concernientes a la protección de los derechos humanos en los Estados americanos. Vale señalar que las consultas también podrán se elevadas por los órganos enumerados en el capítulo X de la Carta de la OEA, y a su vez, la Corte, por solicitud de un Estado miembro, podrá dar opiniones sobre la compatibilidad entre sus leyes internas y los mencionados instrumentos internacionales.

\section{Conclusiones}

Primera: la Constitución Política colombiana de 1991 no es un código cerrado, pues en atención al bloque de constitucionalidad y al principio de remisión, es posible aplicar normas, reglas y principios que no estén contenidos en el texto constitucional. Las remisiones pueden ser tácitas o expresas e implican que si una norma remite a otra, la remitida tiene el mismo valor, de esta manera se evidencia que el artículo 93 contiene de forma implícita el principio de remisión en materia de derechos humanos.

Segunda: el presente estudio permite evidenciar que Corte Constitucional colombiana ha establecido que no todos los convenios de la OIT hacen parte del bloque de constitucionalidad; no obstante, en lo referente al derecho de asociación sindical ha señalado que los convenios 87, 98 y 154 de la OIT hacen parte del bloque de constitucionalidad, adicionalmente, frente a los dos primeros convenios mencionados ha dicho que lo son en stricto sensu.

Tercera: los tratados internacionales y convenios de la OIT son celebrados por el Gobierno, e incorporados al ordenamiento jurídico mediante leyes aprobatorias expedidas por el Congreso, sobre las cuales la Corte Constitucional colombiana adelanta un control de constitucionalidad previo, automático e integral.

Cuarta: los instrumentos internacionales de protección de derechos humanos están conformados tanto por las normas internacionales que pueden invocarse para la defensa del derecho humano de asociación sindical en Colombia, como por el sistema de la Organización de Naciones Unidas (ONU), también denominado "Sistema Universal" y por el Sistema Interamericano o Regional.

Quinta: el derecho de asociación sindical ha sido reconocido como un derecho humano por la comunidad internacional, en consecuencia, ante eventuales vulneraciones puede acudirse 
al Sistema Universal de Derechos humanos, así como al Sistema Regional y a estándares internacionales de derechos humanos.

Sexta: el derecho de asociación sindical en Colombia se encuentra establecido en la Constitución, en leyes que aprueban convenios y tratados internacionales, en decretos ley (Código Sustantivo del Trabajo), en decretos reglamentarios y en disposiciones de carácter penal (Código Penal); por otra parte, en atención al bloque de constitucionalidad se aplican tratados internacionales y convenios de la OIT.

\section{Recomendación}

El papel de los defensores de derechos humanos teniendo en cuenta el derecho de asociación sindical es relevante; sin embargo, es necesario que no solo se ocupen de los casos en donde resulta vulnerado el derecho de asociación sindical de forma conexa, pues es fundamental que sea entendido como un derecho humano, por sí mismo. Prueba de ello es que existen numerosos registros de información sobre atentados, homicidios, secuestros, afectaciones a la integridad física, pero no existen registros que den cuenta de las violaciones que atacan de forma directa el derecho de asociación sindical. En consecuencia, es indispensable empezar a documentar los casos en que se impide la reunión, la asociación o la huelga, así como los eventos en donde se adelantan campañas para fomentar la desafiliación de los trabajadores sindicalizados, entre otras acciones. 


\section{Referencias}

Alerta por crímenes de sindicalistas en el suroccidente. (3 de Julio de 2017). El Tiempo. Recuperado de: http://www.eltiempo.com/colombia/cali/alerta-por-crimenes-de$\underline{\text { sindicalistas-en-el-suroccidente-104992 }}$

Alexy, R. (1995). Teoría del discurso y derechos humanos. Bogotá: Universidad Externado de Colombia.

Asesinato de líder sindical estaría relacionado con su actividad. (24 de junio de 2017). El Tiempo. Recuperado de: http://www.eltiempo.com/colombia/cali/asesinato-de-lidersindical-de-la-universidad-del-valle-102410

Barbero, N. (2014). Protección internacional de los derechos humanos: derecho internacional de los derechos humanos. Santa Fe: Rubinzal-Culzoni.

Beuchout, M. (2004). Filosofía y derechos humanos. México: Siglo XXI.

Bobbio, N. (1991). El tiempo de los derechos. Madrid: Sistema.

Borrajo, E. (2014). Introducción al derecho del trabajo. Madrid: Tecnos.

Botero \& Guzmán, (s.f.). El sistema de los derechos: Guía práctica del sistema internacional de protección de los derechos humanos. Centro de Estudios de Derecho Justicia y Sociedad-Dejusticia. Recuperado: https://www.dejusticia.org/wpcontent/uploads/2008/07/Guía-práctica-Capítulo-I.pdf

Brotóns, A. (2007). Derecho internacional. Valencia: Tirant Lo Blanch.

Carpizo, J. (2011). Los derechos humanos: naturaleza, denominación y características. Revista Mexicana de Derecho Constitucional, (25), 3-29. Recuperado de: http://www.scielo.org.mx/pdf/cconst/n25/n25a1.pdf

Cassese, A. (1991). Los derechos humanos en el mundo contemporáneo. Barcelona: Ariel.

Uribe, A. (2000). Libertad sindical y derechos humanos en Colombia. Recuperado de https://www.colectivodeabogados.org/?libertad-sindical-y-derechos

Colombia, el país con más sindicalistas muertos en 2011. (5 de junio de 2012). El Espectador. Recuperado de: http://www.elespectador.com/noticias/nacional/colombia-el-pais-mas-sindicalistas$\underline{\text { muertos-2011-articulo-351202 }}$

Confederación Sindical Internacional. (2016). Índice global de los derechos de la CSI. Recuperado de https://www.ituc-csi.org/IMG/pdf/survey_ra_2016_sp.pdf 
Congreso de la República de Colombia. (1997, 5 de noviembre). Ley 411 de 1997, por medio de la cual se aprueba el Convenio 151 sobre la protección del derecho de sindicación y los procedimientos para determinar las condiciones de empleo en la administración pública, adoptado en la 64 Reunión de la Conferencia General de la Organización Internacional del Trabajo, Ginebra, 1978. Bogotá: Imprenta Nacional.

Congreso de la República de Colombia. (1999, 12 de agosto). Ley 524 de 1999, por medio de la cual se aprueba el Convenio Número Ciento Cincuenta y Cuatro (154) sobre el Fomento de la Negociación Colectiva", adoptado en la Sexagésima Séptima (67) Reunión de la Conferencia General de la Organización Internacional del Trabajo, Ginebra, con fecha diecinueve (19) de junio de mil novecientos ochenta y uno (1981). Bogotá: Imprenta Nacional.

Congreso de la República de Colombia. (2011, 10 de junio). Ley 1448 de 2011, por la cual se dictan medidas de atención, asistencia y reparación integral a las víctimas del conflicto armado interno y se dictan otras disposiciones. Bogotá: Imprenta Nacional.

Constitución Política de Colombia. (2017). Texto de la Constitución Política de 1991. Bogotá: Legis.

Convención Americana sobre Derechos Humanos (1969). Suscrita en la conferencia especializada interamericana sobre derechos humanos. San José, Costa Rica, 7. Recuperado de http://www.hchr.org.co/documentoseinformes/documentos/html/pactos/conv_ameri cana_derechos_humanos.html

Corte Constitucional colombiana. (1995). Sentencia C-225 de 1995 proferida dentro del expediente L.A.T.-040. Magistrado ponente Alejandro Martínez Caballero.

Corte Constitucional colombiana. (1999). Sentencia T-568 de 1999 proferida dentro del expediente 206.360. Magistrado ponente Carlos Gaviria Díaz.

Corte Constitucional colombiana. (1999). Sentencia C-582 de 1999 proferida dentro del expediente D-2308. Magistrado ponente Alejandro Martínez Caballero.

Corte Constitucional colombiana. (2003). Sentencia C-067 de 2003 proferida dentro del expediente D-4111. Magistrado ponente Marco Gerardo Monroy Cabra.

Corte Constitucional colombiana. (2005). Sentencia $C$ - 401 de 2005 proferida dentro del expediente D-5355. Magistrado ponente Carlos Ernesto Molina.

Corte Constitucional colombiana. (2007). Sentencia C-280 de 2007 proferida dentro del expediente D-6478. Magistrado ponente Humberto Antonio Sierra Porto. 
Corte Constitucional colombiana. (2008). Sentencia C- 466 de 2008 proferida dentro del expediente D-7041. Magistrado ponente Jaime Araujo Rentería.

Corte Constitucional colombiana. (2009) Sentencia C-349 de 2009 proferida dentro del expediente D-7474. Magistrado ponente Luis Ernesto Vargas Silva.

Corte Constitucional colombiana. (2015). Sentencia C-018 de 2015 proferida dentro del expediente D-10.309. Magistrado ponente Gabriel Eduardo Mendoza Martelo.

Declaración Universal de los Derechos Humanos de 1848. Recuperado de: http://www.un.org/es/universal-declaration-human-rights/

Denuncian asesinato de 13 sindicalistas en Colombia este año. (17 de agosto de 2012). El Espectador. Recuperado de: http://www.elespectador.com/noticias/nacional/denuncian-asesinato-de-13sindicalistas-colombia-ano-articulo-368346

Departamento Administrativo para la Prosperidad Social. (2016, 18 de abril). Decreto 624 de 2016, por el cual se crea y reglamenta la Mesa Permanente de Concertación con las Centrales Sindicales CUT, CGT, CTC y la FECODE para la Reparación Colectiva al Movimiento Sindical. Bogotá: Imprenta Nacional.

Escuela Nacional Sindical. (2016). Voces que no callan. Informe sobre violaciones a los derechos humanos de los y las sindicalistas, y la situación de impunidad 20102015. Recuperado de http://www.ens.org.co/wp-content/uploads/2016/12/Cuadernode-Derechos-Humanos-24-Voces-que-no-callan-Informe-sobre-violaciones-a-losderechos.pdf

Escuela Nacional Sindical. (2016). Sistema de información sindical y laboral (Sislab) reporte a diciembre de 2014. Recuperado de http://www.ens.org.co/wpcontent/uploads/2017/02/14-SISLAB-A-DIC-2014.pdf

Escuela Nacional Sindical. (2017). Sistema de información sindical y laboral (Sislab) reporte a diciembre de 2015. Recuperado de http://www.ens.org.co/wpcontent/uploads/2017/02/SISLAB-2015_2.pdf

Escuela Nacional Sindical. (2017). Sistema de información sindical y laboral (Sislab) reporte a junio de 2016. Recuperado de http://www.ens.org.co/wpcontent/uploads/2017/09/Reporte-Sislab-2016-1.pdf

Gómez, A. (2006). La aplicación de los tratados de derechos humanos por los tribunales nacionales, el derecho internacional como fuente de derechos y obligaciones en el derecho interno. En M. Silva (Ed.), Derribando los obstáculos al derecho laboral (pp. 99-168). Bogotá: Editorial Buena Semilla.

"Hace 51 años no se presentaba una reducción tan grande del conflicto armado": Cerac. (20 de enero de 2016). El Espectador. Recuperado de: 
https://www.elespectador.com/noticias/politica/hace-51-anos-no-se-presentaba-unareduccion-tan-grande-articulo-611701

Higuera, D. (2012). Bloque de constitucionalidad en Colombia: jurisprudencia y doctrina. Colombia: Editorial Academia Española.

Jaramillo, I. (2015). Principios constitucionales y legales del derecho al trabajo en Colombia. Bogotá: Legis.

Ministerio del Interior. (2011, 2 de noviembre). Decreto 4100 de 2011, por el cual se crea y organiza el Sistema Nacional de Derechos Humanos y Derecho Internacional Humanitario, se modifica la Comisión Intersectorial de Derechos Humanos y Derecho Internacional Humanitario y se dictan otras disposiciones. Bogotá: Imprenta Nacional.

Ministerio del Trabajo. (2015, 26 de mayo). Decreto 1072 de 2015, por medio del cual se expide el Decreto Único Reglamentario del Sector Trabajo. Bogotá: Imprenta Nacional.

Ministerio del Trabajo. (2016). Acciones para la protección de los derechos laborales individuales y colectivos en Colombia: plan de acción laboral 2011-2016. Recuperado de https://www.google.com.co/search?source=hp\&q=Acciones+para+la+protección+d e+los+derechos+laborales+individuales+y+colectivos+en+Colombia\&oq=Acciones \pm para+la+protección+de+los+derechos+laborales+individuales+y+colectivos+en+C olombia\&gs_l=psy-ab.3..35i39k1.2957.2957.0.5348.3.2.0.0.0.0.755.755.61.2.0.......1.2.64.psy-ab..1.2.1509.6...755.tgTFNwVWatc\#

Ministerio del Trabajo \& Ministerio de Hacienda y Crédito Público. (2014, 5 de febrero). Decreto 160 de 2014, por el cual se reglamenta la Ley 411 de 1997 aprobatoria del Convenio 151 de la OIT, en lo relativo a los procedimientos de negociación y solución de controversias con las organizaciones de empleados públicos. Bogotá: Imprenta Nacional.

Montt, M. (1998). Principios de derecho internacional del trabajo, la OIT. Santiago de Chile: Editorial Jurídica de Chile.

ONG denuncia en EE.UU. el asesinato de 105 sindicalistas en Colombia. (17 de abril de 2015). El Espectador. Recuperado de: http://www.elespectador.com/noticias/politica/ong-denuncia-eeuu-el-asesinato-de$\underline{105-\text { sindicalistas-col-articulo-555633 }}$

Organización Internacional del Trabajo -OIT-. (1948). Declaración de la OIT relativa a los principios $y$ derechos fundamentales en el trabajo. Recuperado de http://ilo.org/declaration/lang--es/index.htm

\section{Derecho real}


Organización Internacional del Trabajo -OIT-. (1948). Convenio 87 sobre libertad sindical y la protección del derecho de sindicación. Recuperado de http://www.ilo.org/dyn/normlex/es/f?p=NORMLEXPUB:12100:0::NO::p12100_ins trument_id:312232

Organización Internacional del Trabajo -OIT-. (1948). Convenio 154 sobre la negociación colectiva. Recuperado de http://www.ilo.org/dyn/normlex/es/f?p=NORMLEXPUB:12100:0::NO::P12100_IL O_CODE:C154

Organización Internacional del Trabajo -OIT. (1948). Convenio 135 relativo a la protección y facilidades que deben otorgarse a los representantes de los trabajadores en la empresa. Recuperado de http://www.ilo.org/dyn/normlex/es/f?p=NORMLEXPUB:12100:0::NO::P12100_IL O_CODE:C135

Organización Internacional del Trabajo -OIT- (1948). Recomendación 143. Recuperado de http://www.ilo.org/dyn/normlex/es/f?p=NORMLEXPUB:55:0:::55:P55_TYPE,P55 _LANG,P55_DOCUMENT,P55_NODE:REC,es,R143,/Document

Organización Internacional del Trabajo -OIT-. (1949). Convenio 98 sobre el derecho de sindicación $y$ de negociación colectiva. Recuperado de http://www.ilo.org/dyn/normlex/es/f?p=NORMLEXPUB:12100:0::NO::P12100_IL O_CODE:C098

Organización Internacional del Trabajo -OIT-. (1978). Convenio 151 sobre las relaciones de trabajo en la administración pública. Recuperado de http://www.ilo.org/dyn/normlex/es/f?p=NORMLEXPUB:12100:0::NO::P12100_IN STRUMENT_ID:312296

Organización Internacional del Trabajo -OIT-. (2006). Libertad sindical. Recopilación de decisiones y principios del Comité de Libertad Sindical del Consejo de Administración de la OIT. Recuperado de http://www.ilo.org/global/docs/WCMS_090634/lang--es/index.htm

Organización Internacional del Trabajo -OIT-. (2010). Normas internacionales del trabajo en materia de libertad sindical y negociación colectiva: guías de estudio para el sector empresarial. Recuperado de http://staging.ilo.org/public/libdoc/ilo/2010/110B09_381_span.pdf

Pacto Internacional de Derechos Civiles y Políticos. (1966). Recuperado de http://www.ohchr.org/SP/ProfessionalInterest/Pages/CCPR.aspx

Pacto Internacional de Derechos Económicos Sociales y Culturales. (1966). Recuperado de http://www.ohchr.org/SP/ProfessionalInterest/Pages/CESCR.aspx 
Pérez, A. (1995). La delimitación conceptual de los derechos humanos. En Derechos humanos, Estado de derecho y constitución. (5. a ed.). Madrid: Tecnos.

Programa de las Naciones Unidas para el Desarrollo -PNUD-. (2011). Reconocer el pasado, construir el futuro - Informe sobre violencia contra sindicalistas y trabajadores sindicalizados 1984-2011. Recuperado de http://www.co.undp.org/content/colombia/es/home/library/democratic_governance/informe-sobre-violencia-contra-sindicalistas-y-trabajadores-sin.html

Tirado, A. (s.f.). Colombia en las Naciones Unidas: 50 años de historia y de participación. Revista Credencial Historia $\mathrm{N}^{\circ}$ 69. Colombia. Recuperado de: http://www.banrepcultural.org/biblioteca-virtual/credencial-historia/numero-69/colombiaen-las-naciones-unidas

Uprimny, R. (2005). El bloque de constitucionalidad en Colombia. Un análisis jurisprudencial y un ensayo de sistematización doctrinal. Centro de Estudios de Derecho Justicia y Sociedad-Dejusticia. Recuperado de:https://www.dejusticia.org/wp-content/uploads/2017/04/fi_name_recurso_46.pdf

\section{Derechos de autor}

Los derechos de autor de este artículo son retenidos por los autores, con los derechos de primera publicación otorgados a la revista. Este es un artículo de acceso abierto distribuido bajo los términos y condiciones de la licencia Creative Commons: Reconocimiento-NoComercial-CompartirIgual 4.0 $\underline{\text { Internacional }}$ 